\title{
62
}

Rupantaran : A Multidisciplinary Journal

Vol. III : 62-75, March, 2020

ISSN : 2091-0061

Research Management Cell (RMC)

Dhankuta Multiple Campus, Dhankuta

Tribhuvan University, Nepal

\section{Learning Strategies and Learner Preferences}

\author{
Krishna Kumari Khadka ${ }^{1}$ \\ Email: krishnakumari.khadka@gmail.com
}

\begin{abstract}
Learning and teaching is a difficult job. Moreover, there are different ways of learning for all students. This article highlights how different learners learn in a different way, i.e what different strategies they use in learning. All learners are different. And, this is more specifically based up on the students in that they have their own individual techniques in learning. We have rarely been able to address the individual variations in a class. Building on a survey study, this article emphasizes the fact that the techniques and learning strategies of the learners be addressed. For the purpose of the study, 50 students from a school of Lalitpur District were purposively selected and inquired via a questionnaire regarding the strategies they more preferred. They were form the secondary level. The article concludes that like other level learners, they also have various ways of doing the things during learning and this is to be understood by every teacher.
\end{abstract}

Key Words: learning, learning strategies, prefernces, teaching

\section{Introduction}

Within the field of education during the last three decades, a gradual but significant shift has taken place, resulting in less stress on teachers and teaching and greater emphasis on students and learning. One consequence of this shift is an increasing awareness and interest in resources for learning styles and language learning strategies in foreign and second language teaching and learning. Applying the ideas to language learning, language learning itself is a life-long task, and language-learning strategies are important skills for students' self-directed learning. It appears that successful language learners have the ability to orchestrate and combine particular types of language learning strategies in effective ways, according to their own learning needs. Thus, to facilitate students' learning, language-learning strategies are a key point for instructors to which one must pay attention.

1. Ms. Khadka is a visiting faculty at Nepal Open University, Lalitpur. 
Considering the fact that language learning strategies can enhance language achievement and that knowledge about these strategies may improve instruction, it is important to study how different cohorts of students employ different learning strategies. As gender is an issue with important theoretical and pedagogical implications in second language learning, it has received some attention in language learning strategy research. This study intends to explore how learners differ in their learning in terms of their gender and the use of different strategies for their learning.

\section{Defining learning strategies}

Since the works by researchers such as Rubin (1975) and Stern (1975) in the mid seventies, awareness in the field of language learning strategies has been rapidly growing. Such works state for providing the techniques for finding good strategies. It can be clear from the proverbial that a horse led to water remains thirsty if it does no drink, i.e. to mean we need to create an appetite in the learners for working. How much best the teachers and methods are; it is the students who can actually do the learning. Nyikos and Oxford (1993, p. 11) put it that learning begins with the learner. It is largely dependent upon what strategies the learners use in their learning. So, first it becomes relevant to describe what learning strategies are.

The term "strategy" as defined by online Cambridge University Dictionary is "a detailed plan for achieving success in situations such as war, politics, business, industry or sport, and of course, learning". Thus, planfulness or goal orientation is an essential part of any definition of "strategy". Planfulness as a feature of learning strategies is reflected in various terms used by different researchers. These terms include "goal," "intention," purpose," "conscious action," "awareness," or "control." For instance, Pressly and Mc Cormick (1995) argue that learning strategies are consciously "controllable" as means for learners to achieve their goals (p.28). Even if none of the terms above is explicitly used in a given definition of learning strategies, the form of the definition of "learning strategy" is usually something like this: "a learning strategy is ' $\mathrm{X}$ (in order) to achieve language." This form naturally implies a goal, purpose, or intention (Lan, 2005, p. 16).

A common observation is that not only are some language learners more successful than others but also that good language learners sometimes do different things than poorer language learners. As Gass and Selinker (2008) say, "the term is commonly used in the second language acquisition literature to refer to what learners do that underlies these differences is learning strategies" (p. 439).

In one of the earliest research in this field, Rubin(1975, p.43) provides a very broad definition of learning strategies as "the techniques or devices which a learner may use to acquire knowledge". In 1981, she defines two kinds of learning strategies: 
those which contribute directly to learning and those which contribute indirectly to learning. The direct learning strategies are divided into six types (i.e. clarification, verification, monitoring, memorization, guessing, inductive inferencing, deductive reasoning, practice), and the indirect learning strategies are divided into two types (i.e. creating opportunities for practice, production tricks) (pp. 124-126).

Tarone (1983,p. 67) defines a learning strategy as "an attempt to develop linguistic and sociolinguistic competence in the target language to incorporate these into one's interlanguage competence". The goals expressed by Tarone in this definition are to attain various competences in the language: "develop linguistic and sociolinguistic competence" and "incorporate these into one's interlanguage competence". O'Malley et al. (1985, p.22) put their views in this way:

There is no consensus on what constitutes a learning strategy in second language learning or how these differ from other types of learner activities. Learning, teaching and communication strategies are often interlaced in discussions of language learning and are often applied to the same behavior. Further, even within the group of activities most often referred to as learning strategies; there is considerable confusion about definitions of specific strategies and about the hierarchic relationship among strategies.

Ellis (1986) views strategies for learning and strategies for using, including communication strategies or "devices for compensating for inadequate resources" ( $p$. 165 ) as quite different manifestations of a more general phenomenon even possible that successful use of communication strategies may actually present language learning since skillful compensation for lack of linguistic knowledge may obviate the need of learning.

Cohen (1998) defines language learning strategies as "Those processes which are consciously selected by learners and which may result in action taken to enhance the learning or use of a second or foreign language through storage, retention, recall, and application of information about that language". Such strategies include strategies for identifying the material that needs to be learned, distinguishing it from other material if need be, grouping if for earlier learning, (e.g. grouping vocabulary by category into nouns, verbs, adjectives, adverbs and so forth), having repeated contact with the material (e.g. through classroom tasks or the completion of homework assignments), and formally committing the material to memory when it does not seem to be acquired naturally (whether through rote memory techniques such as repetition, the use of mnemonics, or some other memory technique) (pp. 4-5). Oxford (1990) provides one of the most comprehensive definitions, as follows: 
Language learning strategies are operations employed by the learner to aid the acquisition, storage, retrieval, and use of information....; specific actions taken by the learner to make learning easier, faster, more enjoyable, more self-directed, more effective, and more transferable to new situations (p. 8).

In Oxford's definition several student-intended goals are evident. These are related to aspects of learning and use of information, as well as to the changed nature of learning when learning is enhanced by strategies (easier, faster, more enjoyable, more self directed...). From the above definition we can say that learning strategies are the special thoughts or behaviors that individuals use to help them comprehend, learn, or retain new information. It focuses on the application of learning strategies to second language acquisition by students learning English as a second language as well as by students learning foreign languages.

As mentioned above, there is currently little or no debate about consciousness as an essential feature of learning strategies. However, there comes a time for some learners at which a given strategy is no longer consciously used, they can no longer be called "strategies". Cohen (1998), and Oxford and Cohen (1992) assert that when strategies become habitual and automatic, i.e., when learners no longer have the awareness of using them but continue to use these mental or observable behaviors automatically these former strategies should be called "processes".

From these definitions, a change over time may be noted: from the early focus on the product of linguistic or sociolinguistic competence (LLS), there is now a greater emphasis on the processes and the characteristics of LLS.

\section{Classification of language learning strategies}

Even though researchers face difficulty in classifying language learning strategies, they have classified into several different ways. Bialystok (1978, as cited in Lan, 2005, p. 20) presents a model that includes four types of strategies that the learner uses (1) functional practicing, (2) formal practicing, (3) monitoring, and (4) inferencing. In functional practicing, the learner uses the language in communicative situations. Meaning is of primary importance here. In formal practising, he focuses on the language codes. The learner would thus refer to grammar books, dictionaries and so on. He operates on information already in explicit knowledge for atomizing it and transferring it to implicit knowledge by means such as language drills. The learners also monitor or use the conscious knowledge of the language to examine and modify or correct linguistic output. This concept of monitoring is similar to that postulated by Krashen (1977) in his "monitor theory". Since time is required for this conscious 
knowledge to be utilized, monitoring can only affect output after some delay. The learner also uses inferencing as a strategy whereby he may arrive at particular linguistic information which was previously unknown. Inferencing is an effective way to increase comprehension of linguistic material. The learner also uses inferencing in exploiting information from other knowledge, for example, getting cues from the environment, gestures and knowledge of other languages and the like inferencing from implicit knowledge may be unconscious. Inferring from explicit knowledge may occur by means of using the context of the passage or message to obtain meanings of words or forms.

Naiman et al. (1978) 's taxonomy contains five broad categories of strategies that they assert to be used by all good language learners: (a) an active task approach, (b) realization of language as a system, (c) realization of language as a means of communication and interaction, (d) management of affective demands, and (e) monitoring of second language performance. Their classification scheme was built on data collected from interviews with a group of 34 proficient adult language learners (as cited in Lan, 2005, p. 20).

Rubin (1987), who pioneered much of the work in the field of strategies, makes the distinction between strategies contributing directly to learning and those contributing indirectly to learning. According to her, there are three types of strategies used by learners that contribute directly or indirectly to language learning. These are:

Learning Strategies. Different scholars have different ways of defining and categorizing the learning strategies. Broadly, they are of two main types, being the strategies contributing directly to the development of the language system constructed by the learner.

Cognitive learning strategies. They refer to the steps or operations used in learning or problem-solving that requires direct analysis, transformation, or synthesis of learning materials. Rubin identifies 6 main cognitive learning strategies contributing directly to language learning viz. Clarification/Verification, Guessing/Inductive Inferencing, Deductive Reasoning, Practice, Memorization and Monitoring

Meta-cognitive learning strategies. These strategies are used to oversee, regulate or self-direct language learning. They involve various processes as planning, prioritizing, setting goals, and self-management.

\section{Communication strategies}

They are less directly related to language learning since their focus is on the processes of participating in a conversation and getting meaning across or clarifying 
what the speaker intended. Communication strategies are used by speakers when faced with some difficulty due to the fact that their communication ends outrun their communication means or when confronted with misunderstanding by a co-speaker.

\section{Social strategies}

Social strategies are those activities learners engage in and which afford them opportunities to be exposed to and practise their knowledge. Although these strategies provide exposure to the target language, they contribute indirectly to learning since they do not lead directly to the obtaining, storing, retrieving, and use of language (Rubin \&Wenden, 1987, pp. 23-27).

O'Malley and Chamot (1990) distinguish three types of strategies (as cited in Ellis, 1994, p. 536) the learner use to manipulate the language. Their ideas can be summed up as follows:

Cognitive strategies refer to the steps or operations used in problem solving that require direct analysis, transformation or synthesis of learning materials. They have an operative or cognitive processing function. Among the cognitive strategies listed by them are: 'repetition' (imitating a language model, either covertly or overtly), 'note taking' (writing down information presented orally) and 'elaboration' (relating new concepts to other information in memory). Cognitive strategies such as these appear to be directly linked to the performance of particular learning tasks.

Meta-cognitive strategies make use of knowledge beyond the cognitive process and constitute an attempt to regulate language learning by means of planning, monitoring and evaluating. They have an executive function. Some examples as provided by different authors are: 'directed attention' (deciding in advance to pay attention to specific aspects of language input) and 'self management' (displaying understanding of the conditions which help learning and trying to bring these about). O'Malley and Chamot (1987) give examples from interviews with ESL learners of the kinds of behaviors that are representative of these strategies. Social/affective srategies concern the ways in which learners elect to interact with other learners and native speakers. They give examples as: 'co-operation' (working with one or more peers to obtain feedback, pool information or model a language activity) and 'question for clarification ('asking a teacher or other native speaker for repetition/paraphrase, explanation and or examples).

According to Stern (1992, pp. 263-266), there are five main language learning strategies. These are summed up as follows: 


\section{Management and planning strategies}

These strategies are related with the learner's intention to direct his own learning. A learner can take charge of the development of his own programme when he is helped by a teacher whose role is that of an adviser and resource person. That is to say that the learner must: decide what commitment to make to language learning; set himself/herself reasonable goals; decide on an appropriate methodology, select appropriate resources, and monitor progress and evaluate his achievement in the light of previously determined goals and expectations.

Cognitive strategies. These strategies are the steps or operations used in learning or problem solving that require direct analysis, transformation, or synthesis of learning materials. Stern (ibid) gives the similar examples for this category as given by Rubin (1975), as mentioned previously.

Communicative - experiential strategies. Communication strategies- such as circumlocution, gesturing, paraphrase, or asking for repetition and explanation are techniques used by learners so as to keep a conversation going. The purpose of using these techniques is to avoid interrupting the flow of communication.

Interpersonal strategies. The learners should monitor their own development and evaluate their own performance. Learners should contact with native speakers and cooperate with them. Learners must become acquainted with the target culture.

Affective strategies .It is evident that good language learners employ distinct affective strategies. Language learning can be frustrating in some cases. In some cases, the feeling of strangeness can be evoked by the foreign language. In some other cases, L2 learners may have negative feelings about native speakers of L2. Good language learners are more or less conscious of these emotional problems. Good language learners try to create associations of positive affect towards the foreign language and its speakers as well as towards the learning activities involved. Learner training can help students to face up to the emotional difficulties and to overcome them by drawing attention to the potential frustrations or pointing them out as they arise.

Based on this synthesis of previous research and on factor analytic questionnaire, Oxford (1990) developed one of the widely accepted classification taxonomies in the language learning areas. Oxford model of language learning strategies consists of six categories: memory strategies, cognitive strategies, compensation strategies, metacognitive strategies, affective strategies and social strategies. These six categories (which underline Strategies Inventory for a great deal of research in the learning strategies field) were further divided into direct strategies and indirect strategies. In 
Oxford's view, direct strategies refer to "strategies that directly involve the target language and require mental processing of the language" (Oxford, 1990, p. 37). The three groups that belong to the direct strategies are memory, cognitive, and compensation. Indirect strategies are those which "provide indirect support for language learning through focusing, planning, seeking opportunities, controlling anxiety, increasing cooperation and empathy and other means" (Oxford, 1990, p. 151). The three groups belonging to this category are meta-cognitive, affective, and social strategies. Here a brief introduction of each group will help explain them.

\section{Direct language learning strategies}

The direct strategies are beneficial to the students because they help store and recover information. These strategies help learners to produce language even when there is gap in knowledge. They also help to understand and use the new language.

Memory strategies. Memory strategies are specific devices (mnemonics) used by learners to make mental linkages that will allow new information, most often vocabulary, to enter and remain in long term memory. Examples of memory strategies are to make associations with what has already been learned, to draw pictures to help remember new words, and to repeatedly pronounce or write new words in order to remember them. Although memory strategies could easily be viewed as cognitive strategies, their purpose is limited to memorization and involves mostly surface processing. Prior research shows that memory strategies operate differently from many cognitive strategies in terms of frequency of use.

Cognitive strategies. Cognitive strategies help learners process and use the language for learning or for accomplishing a task involving the language, e.g., watch TV in English; listen to radio/CDs in English, use English computer programs, and find similarities between first and second languages. Compared with memory strategies, the purpose of cognitive strategies is not simply memorization but instead deeper processing and use of the language. This category is commonly used for research on second language learning.

Compensation strategies. Compensation strategies are intended to make up for missing knowledge with listening, reading, speaking, or writing, for example, using gestures or body language (for speaking), rephrase (or speaking of writing), ask for help (for listening, reading, speaking, or writing) and make guesses based on the context (for listening and reading). The last strategy could also be listed as a cognitive strategy, but it is included here as a compensation strategy because it makes up for a gap in knowledge. 


\section{Indirect language learning strategies}

Indirect language learning strategies work together with the direct strategies. They help learner regulate the learning process. These strategies support and manage language learning without direct engagement and therefore called indirect strategies.

Meta-cognitive strategies. Meta means "above" or "beyond" So meta-cognitive means "beyond" the cognitive. Meta-cognitive strategies encompass the planning, organizing, evaluation, and monitoring of one's own language learning, e.g., organize time for learning, check one's progress, and analyze one's mistakes and try not to make them again. This category is widely used in the second language field.

Affective strategies. Affective strategies help the learner deal with his or her own emotions, motivations, and attitudes while (or about) learning English. Examples of such strategies are take risks, try to relax when feeling anxious about learning, and reward oneself for succeeding. This category, sometimes combined with social strategies, is often involved in strategy work in second language learning.

Social strategies. Social strategies refer to how learners interact with other people in the context of learning languages and related culture. Social strategies include, among others, ask someone to speak slowly, practice with others and show interest in learning about the culture of English speaking countries. This category, sometimes combined with affective strategies, is often part of strategy research.

\section{Oxford's language learning strategy system}

Oxford has summarized above mentioned strategies in the following table:

\begin{tabular}{lll}
\hline Type & Primary strategies & Secondary strategies \\
\hline Direct Strategies & 1. Memory strategies & A. Creating mental linkages \\
& & B. Applying images and sounds \\
& & C. Reviewing well \\
& D. Employing action
\end{tabular}

2. Cognitive strategies
A. Practicing
B. Receiving and sending messages
C. Analyzing and reasoning
D. Creating structure for input and output

3. Compensation strategies
A. Guessing intelligently
B. Overcoming limitations in speaking and writing 


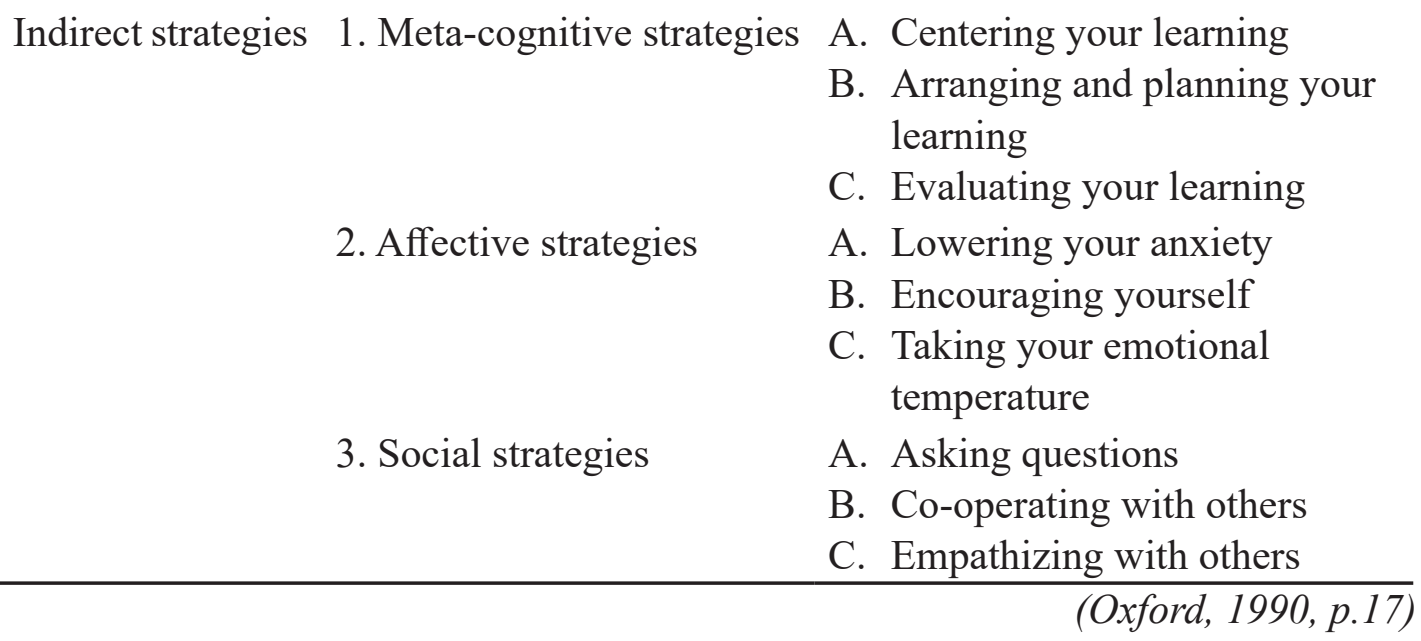

Although Oxford's taxonomy is perhaps the most comprehensive classification of learning strategies to date; it is still of necessity, some what selective since "dozens and perhaps hundreds of such strategies exist" (Oxford, Lavine \& Crookall, 1989, p.29).

However, Oxford (1990) clarifies that:

There is no complete agreement on exactly what strategies are; how many strategies exist; how they should be defined, demarcated, and categorized and whether it is - or even will be - possible to create a real, scientifically validated hierarchy of strategies... classification conflicts are inevitable (p. 17).

Amid this welter of overlapping materials and conflicting opinion, the process of establishing definition and classification system for language learning strategies is far from straight forward. In the face of the learning strategy field, whatever term may be defined or classified it is inevitably going to come into conflict with one or other of the competing terms, definitions and classification system.

\section{Research questions}

This study was guided by the following research questions:

- What type of learning strategies do the students use?

- What are the more frequent strategies used by the students?

\section{Research Methodology}

In order to investigate the use of the learning strategies by the students, a questionnaire consisting of three different categories of cognitive, meta-cognitive and socio-affective strategies was given to the students. The learners were asked to respond the how many of them used such types of strategies. It was a survey study done among them. 


\section{The participants}

The participants of this study were 50 students studying at grade 10,11 and 12. The students were selected through random sampling and using a Fish-ball Draw technique'. This was done considering the ethics of the quantitative research methodology. However, Mahendra Bhrikuti School of Lalitpur District, Nepal was Purposively selected as it was the are of interest of the researcher and the area where she has been involved long in teaching .

\section{Results and Discussion}

As stated earlier, this study consisted of a questionnaire with the three different categories of the learning strategies viz. cognitive, meta-cognitive and socio-affective. The responses given by the students, i.e. how many of them used the ones mentioned have been analyzed in terms of the following three broad headings.

\section{Cognitive strategies}

This category consisted of seven different types of strategies that the students more frequently used. As rated by the students, the use of strategies is summarized in terms of the frequency and percentage below:

Table 1: Summary on the Use of Cognitive Strategies

\begin{tabular}{|l|r|r|}
\hline \multicolumn{1}{|c|}{ Type of Strategy } & No. of students (F) & Percentage (\%) \\
\hline Inferencing & 10 & 20 \\
\hline Elaboration & 5 & 10 \\
\hline Summarizing & 15 & 30 \\
\hline Note-taking & 4 & 8 \\
\hline Highlighting & 6 & 12 \\
\hline Practicing sounds & 3 & 6 \\
\hline Guessing & 7 & 14 \\
\hline
\end{tabular}

As the table 1 shows, the students used 'summarizing' as the most frequent strategy, i.e. $30 \%$ used it. Another more frequent strategy is 'inferencing' which has been used by $20 \%$ of the students. Similarly, the other strategies: 'elaboration' notetaking', ' highlighting', 'practicing sounds' and 'guessing' were respectively found to be used by $10 \%, 8 \%, 12 \%, 6 \%$ and $14 \%$ respectively. In overall, it can be interpreted that 'summarizing', 'inferencing' and guessing are more frequently found to be practiced by the students.

\section{Meta-cognitive Strategies}

Another category included in the questionnaire was on the students' use of the meta-cognitive strategies. This category consisted of six different choices of the strategies. The detail of the strategy use by those students is presented in the following table: 
Table 2: Summary on the Use of Meta-cognitive Strategies

\begin{tabular}{|l|r|r|}
\hline \multicolumn{1}{|c|}{ Type of Strategy } & No. of students (F) & \multicolumn{2}{c|}{ Percentage (\%) } \\
\hline Planning & 8 & 16 \\
\hline Monitoring & 4 & 8 \\
\hline Self-motivation & 10 & 20 \\
\hline Self-management & 12 & 24 \\
\hline Directed attention & 8 & 16 \\
\hline Self-evaluation & 8 & 16 \\
\hline
\end{tabular}

Looking at the table above, the most frequently used strategy of this category is 'self-management' which is used by $24 \%$ of the participants. Another more frequently used strategy is 'self-motivation' as is used $20 \%$ of them. The other strategies: 'planning', 'monitoring' 'directed attention' and 'self-evaluation' are respectively used by $16 \%, 8 \%, 16 \%$ and $16 \%$. It indicates that the least strategy is 'directed attention'. Meanwhile, other strategies seem to be more used.

\section{Socio-affective Strategies}

This was the third category of the questionnaire. It included seven different options for those students. The responses given by all of them are presented in the table herewith:

Table 3: Summary on the Use of Socio-affective Strategies

\begin{tabular}{|l|r|r|}
\hline \multicolumn{1}{|c|}{ Type of Strategy } & No. of students (F) & \multicolumn{2}{c|}{ Percentage (\%) } \\
\hline Asking others & 14 & 28 \\
\hline Pair work & 6 & 12 \\
\hline Group work & 6 & 12 \\
\hline Discussion & 8 & 16 \\
\hline Co-operation & 10 & 20 \\
\hline Self-talk & 2 & 4 \\
\hline Self-motivation & 4 & 8 \\
\hline
\end{tabular}

Table 3 above shows that the most frequently used socio-affective strategy by the students is 'asking others' that has been used by $28 \%$ of them. The next more frequently used strategy by those students is 'co-operation'. It has been used by $20 \%$ of them. The other strategies: 'pair work', 'group work, 'discussion' 'self-talk' and 'self-motivation' are respectively used by $12 \%, 12 \%, 16 \%, 4 \%$ and $8 \%$ of the students. In overall, it can be interpreted that 'self-talk' and 'self-motivation' are the least used ones while 'pair work', 'group work, 'discussion' are used by the average ones.

\section{Conclusion}

All learners have their own styles and strategies used in their study. That is to mean, the preferences over the learning strategies and techniques different from 
learners to learners. Some learners use more cognitive strategies while others do with either the meta-cognitive or socio-affective strategies. As language teachers, if we could understand the strategies that our student use more frequent, we can change our teaching and learning activities accordingly. Further, such strategies also have to do with the psychological aspects of the students. Indeed, some strategies obviously can be of better use than that of the others. This is what we need to prioritize and promote among our learners.

\section{References}

Bailystok, E. (1979). The role of conscious strategies in second language proficiency. Candian Modern Language review, 35, 372-394.

Chang, Y.P. (2003). Factors affecting language learning strategy choice: A study of ELT senior high school students in Taiwan. An unpublished doctoral dissertation, Texas A \& M University.

Chaudhary, G. (2009). Learning strategies used by class toppers. An unpublished M.Ed. thesis, T.U., Kirtipur.

Cook, V. (2008).Second language learning and language teaching. London : Hodder Education.

Devkota, H.P. (2003). A study of langue strategies used in studying literature. An unpublished M.Ed. thesis, T.U., Kirtipur.

Ehrman, M.E \& Oxford, R. L. (1989). Effects of Sex differences, Career Choice \& Psychological type on adult language learning strategies. The modern Journal, 73 (1), 1-13.

Eillis, R. (1985). Understanding second language acquisition. Oxford: Blackwell.

Eillis, R. (1994). The study of second language acquisition. Oxford: OUP.

Finkbeiner, C. (1998). The promotion of explicit and implicit learning strategies in English instruction. Retrieved from: http://webdoc.sub.gwdg. de/edoc/ia/eese/artic98/finkb/10_98.html.

Gass, S.M. and Selinkerk, L. (2008). Second language acquisition: An introducing course. London: Routeledge.

Green, M.J. \& Oxford, R.L. (1995). A closer look at learning strategies: L2 proficiency and gender. TESLO Quartly 28(2). 261-290.

Griffiths, C. (2008). Lesson from good language learners (eds.). Cambridge : CUP. Lamichhane (2010). Gender variation on language learning strategies. An unpublished M.Ed. Thesis, T.U., Kirtipur.

Lan, R.L. (2005). Language learning strategies profiles of EFL elementary school students in Taiwan. An unpublished Ph.D. thesis, T.U., University of MarylandUSA. 
Naiman, N. et al. (1978). The good language learners. Research in education, 7. Toronto Ontario institute for studies in education.

Nunan, D. (2010) Research method in language learning. Cambridge : CUP.

O’Mally, J.M \& Chamot, A.U. (1990p.2). Learning strategies in second language acquisition. Cambridge: CUP.

Oxford, R. L. \& Nyikos, M.(1989). Variables affecting Choice of language learning strategies by University students. Modern language Journal, 73(2). 291-300.

Oxford, R. L. (2003). learning styles \& strategies : An Overview. Retrieved from 13th April, 2010.

Oxford, R. L. (2003). Learning strategies. Retrieved from: https://www.researchgate. net/publication/254446824_Language_learning_styles_and_strategies_An_ overview.

Oxford, R.L. (1990). Language learning strategies: What every teachers should know. Boston: Heinle \& Heinle.

Rain, Md.G. (2006). Learning strategies used by Maithili learners of English. An unpublished M.Ed. thesis, T.U., Kathmandu.

Raut, I.R. (2007). A study on the strategies used in teaching vocabulary: A case of secondary level teachers. An unpublished M.Ed. thesis, T.U., Kathmandu.

Rawal, H. \& Joshi, K. R. (2010). Second language Acquisition. Kathmandu: Intellectuals' Book Palace.

Regmi, K.P. (2010). Learning styles adopted by secondary level students. An unpublished M.Ed. thesis, T.U., Kathmandu.

Rubin (1975). What the good language learner can teach us. TESOL Quartely, 9(1), 41-51.

Shrestha, W.A. (2007). Strategies adopted by $X^{\text {th }}$ graders in teaching English vocabulary. An unpublished M.Ed. thesis, T.U., Kirtipur. 